\title{
PEMBUATAN TURBIN ANGIN SAVONIUS BERTINGKAT BERBAHAN ALUMUNIUM
}

\author{
Idzani Muttaqin ${ }^{1}$, Muhammad Suprapto ${ }^{2}$ \\ ${ }^{1}$ Teknik Industri, Fakultas Teknik, Universitas Islam Kalimantan Muhammad Arsyad Al-Banjari \\ ${ }^{2}$ Teknik Mesin, Fakultas Teknik, Universitas Islam Kalimantan Muhammad Arsyad Al-Banjari \\ Jl. Adhyaksa, Jl. Kayu Tangi 1 Jalur 2 No.2, Sungai Miai, Kec. Banjarmasin Utara, Kota Banjarmasin, \\ Kalimantan Selatan 70123 \\ Email : idzanimuttaqin@gmail.com, muhammadsuprapto@gmail.com
}

\begin{abstract}
Abstrak- Turbin angin savonius merupakan turbin angin dengan sumbu vertikal yang memiliki banyak kelebihan di antaranya bentuk konstruksi yang mudah dibuat, tidak memerlukan kecepatan angin yang tinggi untuk mulai berputarnya. Turbin savonius memiliki kelemahan pada nilai efisiensi yang cukup rendah. Pada penelitian ini akan dilakukan perancangan sudu turbin angin savonius berbahan Alumunium dan akrilik, pengujian secara eksperimen terhadap sudu bertingkat dengan parameter kecepatan putaran poros. Penelitian ini dilaksanakan selama 6 bulan yaitu bulan Januari 2021 sampai Juni 2021. Permodelan dan pengujian akan dilakukan di Laboratorium Teknik Mesin Universitas Islam Kalimantan Muhammad Arsyad Al-Banjari, Banjarmasin. Objek yang diteliti yaitu turbin angin savonius sudu bertingkat berbahan alumunium. hasil eksperimen yang dilakukan pada penelitian sudu berbahan alumunium memiliki kecepatan putaran $358.7 \mathrm{rpm}$ pada kecepatan angin $4 \mathrm{~m} / \mathrm{s}$.
\end{abstract}

Kata Kunci : Turbin Savonius, Aluminium, Kecepatan Angin

\section{PENDAHULUAN}

C nergi memiliki peranan penting hampir disemua aspek $\mathcal{C}_{\text {pada }}$ era modern saat ini, pengembangan energi terbarukan seperti energi angin, energi air dan energi surya dapat mengurangi ketergantungan kita pada bahan bakar fosil, yang semakin tahun ketersediaannya semakin menipis.(Debnath, Pinku .2013).

Salah satu sumber energi terbarukan adalah energi angin. Energi angin merupakan salah satu energi ramah lingkungan, sumber energi berlimpah dan dapat diperbaharui sehingga sangat berpotensi untuk dikembangkan. Potensi angin di Indonesia pada umumnya memiliki kecepatan angin yang rendah berkisar antara 3 $\mathrm{m} / \mathrm{s}-7 \mathrm{~m} / \mathrm{s}$, sehingga jenis turbin angin vertikal dirasa sangat cocok untuk digunakan pada kondisi kecepatan angin rendah.

Turbin angin savonius mampu menerima angin dari segala arah karena memiliki sisi cekung dan cembung yang saling berlawanan yang dihadapkan pada arah datangnya angin. Sisi cembung yang dihadapkan pada arah datangnya angin menjadi penghambat karena menghasilkan torsi negatif yang berlawanan dengan arah putaran turbin. (Altan dkk. 2012).

\section{Energi Angin}

Energi adalah kemampuan melakukan kerja. Menurut Kamus Besar Bahasa Indonesia (KBBI), energi didefiniskan sebagai daya atau kekuatan yang diperlukan untuk melakukan berbagai proses kegiatan. Energi merupakan bagian dari suatu benda tetapi tidak terikat pada benda tersebut. Angin adalah fluida homogen yang bergerak dengan kecepatan tertentu, energi kinetik yang tersimpan dalam suatu blok udara dengan massa (m) dan kecepatan (v) yang bergerak sepanjang sumbu $\mathrm{x}$ dapat di rumuskan sebagai :

$$
E=\frac{1}{2} m v^{2}
$$

Di mana :

$$
\begin{aligned}
& \mathrm{E}=\text { Energi kinetik (Joule) } \\
& \mathrm{m}=\operatorname{Massa}(\mathrm{kg}) \\
& \mathrm{v}=\operatorname{Kecepatan} \operatorname{angin}(\mathrm{m} / \mathrm{s})
\end{aligned}
$$

\section{Turbin Angin}

Turbin angin adalah alat yang berfungsi untuk mengubah energi kinetik angin menjadi energi gerak berupa putaran rotor dan poros generator untuk menghasilkan energi listrik. Energi gerak yang berasal dari angin akan diteruskan menjadi gaya gerak dan torsi pada poros generator yang kemudian dihasilkan energi listrik. Turbin angin merupakan mesin penggerak yang energi penggeraknya berasal dari angin.

Turbin angin adalah alat yang berfungsi untuk mengubah energi kinetik angin menjadi energi gerak berupa putaran rotor dan poros generator untuk menghasilkan energi listrik. Energi gerak yang berasl dari angin akan diteruskan menjadi gaya gerak dan torsi pada poros generator yang kemudian dihasilkan energi listrik. Turbin angin merupakan mesin penggerak yang energi penggeraknya berasal dari angin. Secara umum turbin angin sumbu Vertikal (TASV), khususnya turbin angin savonius memiliki kecepatan awal angin yang lebih rendah dibandingkan dengan turbin angin jenis lainnya. Daya energi angin dapat di hitung dengan persamaan sebagai berikut :

$$
p=\frac{1}{2} C p \rho A v^{3}
$$

di mana :

$$
\begin{aligned}
& \mathrm{P}=\text { Daya energi angin }(\text { Watt }) \\
& \rho=\text { Kerapatan udara }\left(1.2 \mathrm{~kg} / \mathrm{m}^{3}\right) \\
& \mathrm{A}=\text { Area penampang angin }\left(\mathrm{m}^{2}\right) \\
& \mathrm{V}=\operatorname{Kecepatan} \text { angin }(\mathrm{m} / \mathrm{s})
\end{aligned}
$$

\section{Sudu turbin savonius}

Sudu turbin angin yang terdiri dari baling-baling/ sudu merupakan bagian dari turbin angin yang berfungsi menerima energi kinetik dari angin dan merubahnya menjadi energi gerak (mekanik) putar pada poros penggerak. Pada sebuah turbin angin, baling-baling rotor dapat berjumlah 2, 3 atau lebih. 
Turbin angin savonius merupakan jenis turbin angin yang paling sederhana, efisiensi sekitar $\pm 20 \%$, turbin angin dapat berputar dan menghasilkan energi listrik pada kecepatan angin yang rendah dan tidak terpengaruh arah angin. Maka turbin ini sangat sesuai untuk di kembangkan dan diteliti sesuai dengan potensi yang ada di Indonesia, khususnya di daerah Kalimantan selatan.

\section{METODE PENELITIAN}

\section{Spesifikasi turbin}

Dari turbin savonius yang di buat di peroleh data spesifikasi teknis seperti ditunjukkan pada tabel 1 sebagai berikut.

Tabel 1. spesifikasi Turbin savonius

\begin{tabular}{|c|c|c|}
\hline No & Spesifikasi & Keterangan \\
\hline 1 & Jenis Turbin & Turbin Savonius Bertingkat \\
\hline 2 & Jenis Putaran & $0.3 \mathrm{~m}$ \\
\hline 3 & Diameter end plat & Alumunium $1 \mathrm{~mm}$ \\
\hline 4 & Material blade & $50 \mathrm{~mm}$ \\
\hline 5 & Celah Udara & 2 \\
\hline 6 & Jumlah Sudu & \\
\hline
\end{tabular}
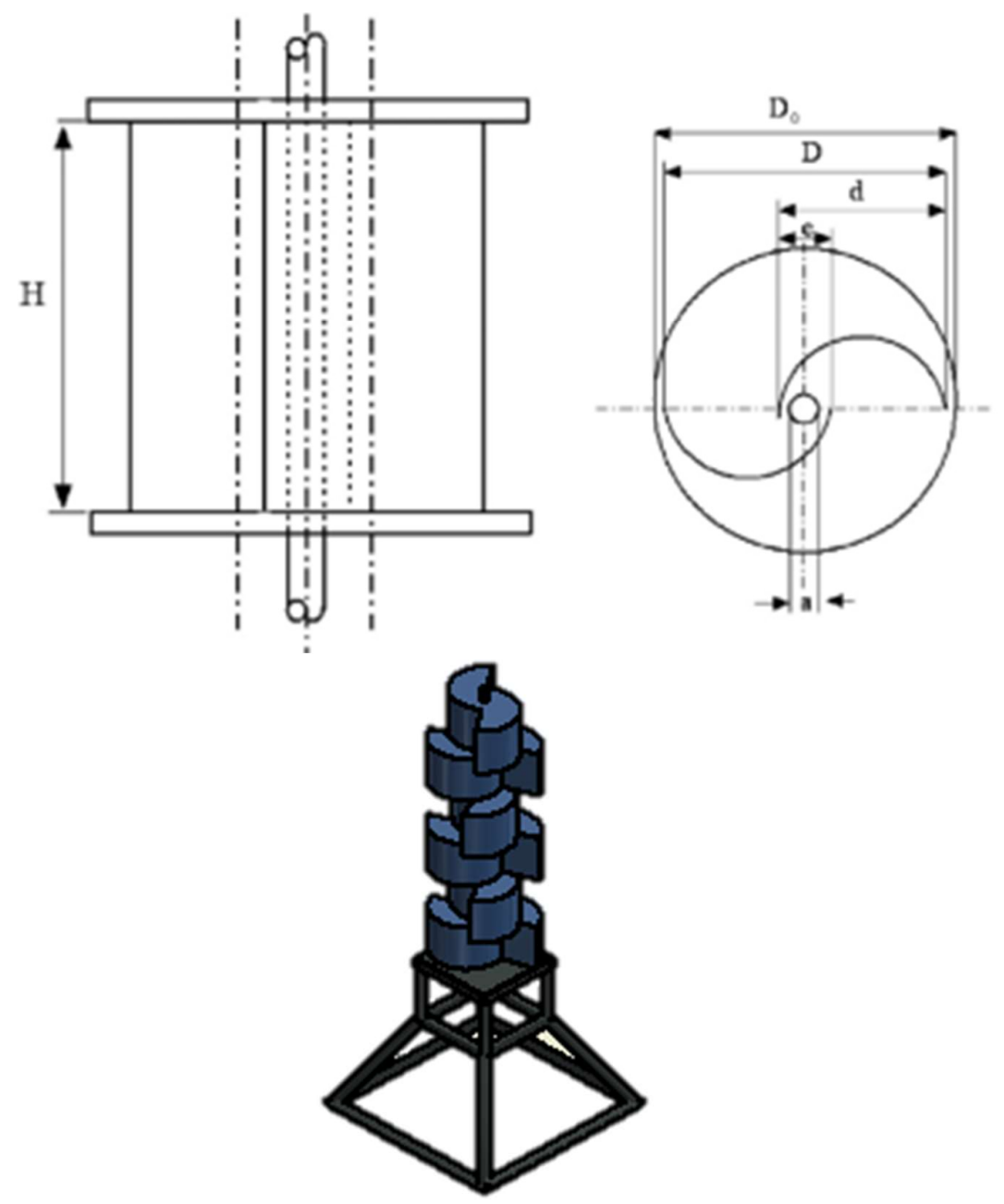

Gambar 1. Sudu Tubin Savonius dan Sudu Model Bertingkat 
Diagram alir penelitian

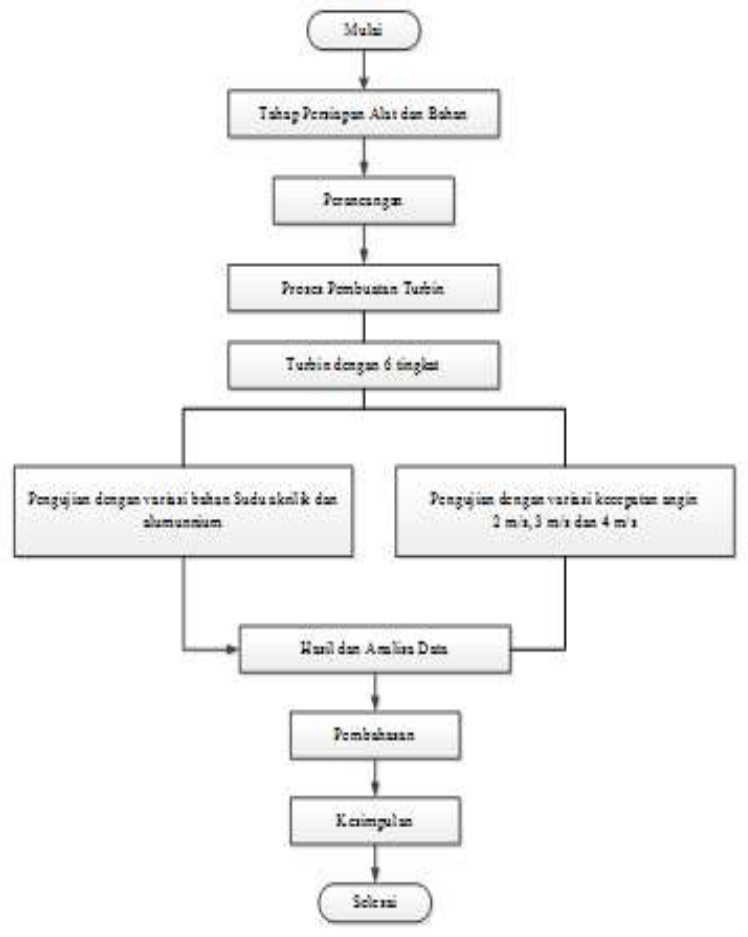

Gambar 2. Diagram Alir Penelitian

\section{HASIL DAN PEMBAHASAN}

\section{Perhitungan Daya Turbin Angin}

Daya turbin savonius dapat dihitung dengan persamaan sebagai berikut: Efisiensi turbin savonius sebesar $20 \%$ dengan kecepatan angin $2 \mathrm{~m} / \mathrm{s}$.

$$
\begin{aligned}
& p=\frac{1}{2} C p \rho A v^{3} \\
& p=\frac{1}{2}(0.2)(1.2)(0.18)\left(4^{3}\right) \\
& p=1.3824
\end{aligned}
$$

Secara teoritis kecepatan shaft speed dapat dihitung dengan persamaan dibawah ini. Perhitungan mengguakan nilai kecepatan angin $4 \mathrm{~m} / \mathrm{s}$.

$$
\begin{aligned}
& s s=\frac{60 . \lambda \cdot v}{\pi D} \\
& s s=\frac{60(1.5) 4}{(3.14)(0.3)} \\
& s s=382.16 R p m
\end{aligned}
$$

Tabel 2. Hasil Perhitungan Turbin Savonius

\begin{tabular}{|c|c|c|c|c|c|c|}
\hline No & $\begin{array}{c}\text { Tingkat } \\
\text { sudu }\end{array}$ & $\begin{array}{c}\text { Material } \\
\text { Sudu }\end{array}$ & $\begin{array}{c}\text { Kecepatan } \\
\text { angin }\end{array}$ & $\begin{array}{c}\text { Daya } \\
\text { (Watt) }\end{array}$ & $\begin{array}{c}\text { Shaft Speed } \\
(\mathrm{Rpm})\end{array}$ & $\begin{array}{c}\text { Torsi } \\
(\mathrm{Nm})\end{array}$ \\
\hline 1 & 6 & Alumunium & 2 & 0.1728 & 191.083 & 0.00096 \\
\hline 2 & 6 & Alumunium & 3 & 0.5832 & 286.624 & 0.00216 \\
\hline 3 & 6 & Alumunium & 4 & 1.3824 & 382.166 & 0.00384 \\
\hline
\end{tabular}

\section{KECEPATAN ANGIN TERHADAP SHAFT SPEED}

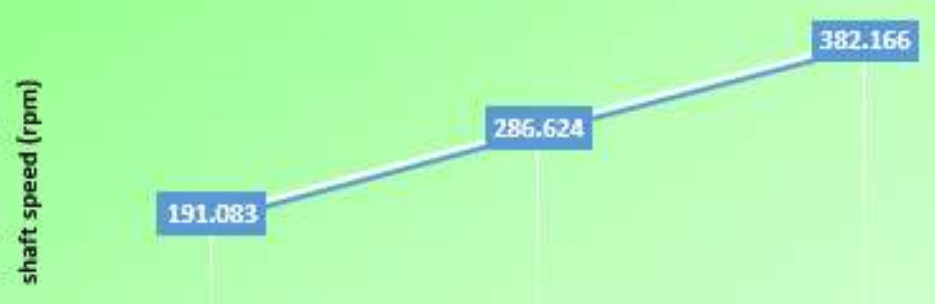

\section{Kecepatan Angin (m/s)}

Gambar 3. Grafik Kecepatan Angin 
Dari grafik diatas nilai daya aktual turbin angin savonius hanya dipengaruhi nilai kecepatan angin. Pada kecepatan angin $2 \mathrm{~m} / \mathrm{s}$ dengan daya sebesar 0.1728 watt, kecepatan angin $3 \mathrm{~m} / \mathrm{s}$ dengan daya sebesar 0.5832 watt dan nilai tertinggi pada kecepatan angin $4 \mathrm{~m} / \mathrm{s}$ yaitu sebesar 1.3824 watt.

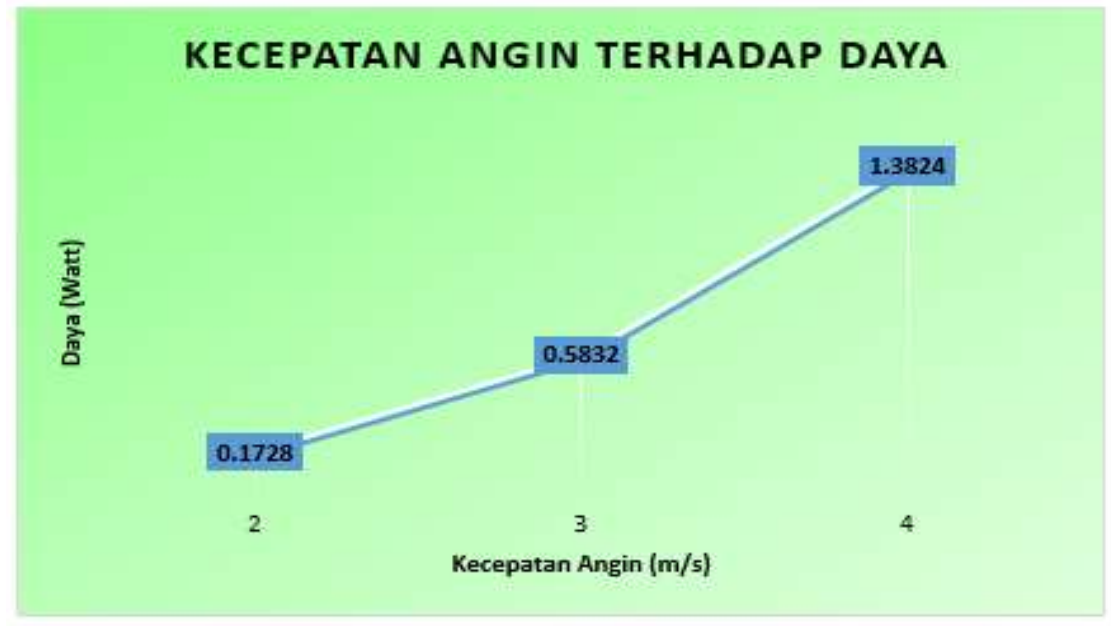

Gambar 4. Grafik Kecepatan Angin Terhadap Daya

Pada perhitungan nilai putaran turbin savonius bertingkat, nilai putaran pada kecapatan angin $2 \mathrm{~m} / \mathrm{s}$ dengan kecepatan putaran 191.083 Rpm, pada kecapatan angin 3 $\mathrm{m} / \mathrm{s}$ dengan kecepatan putaran 286.624 Rpm dan kecapatan angin $4 \mathrm{~m} / \mathrm{s}$ dengan kecepatan putaran $382.116 \mathrm{Rpm}$

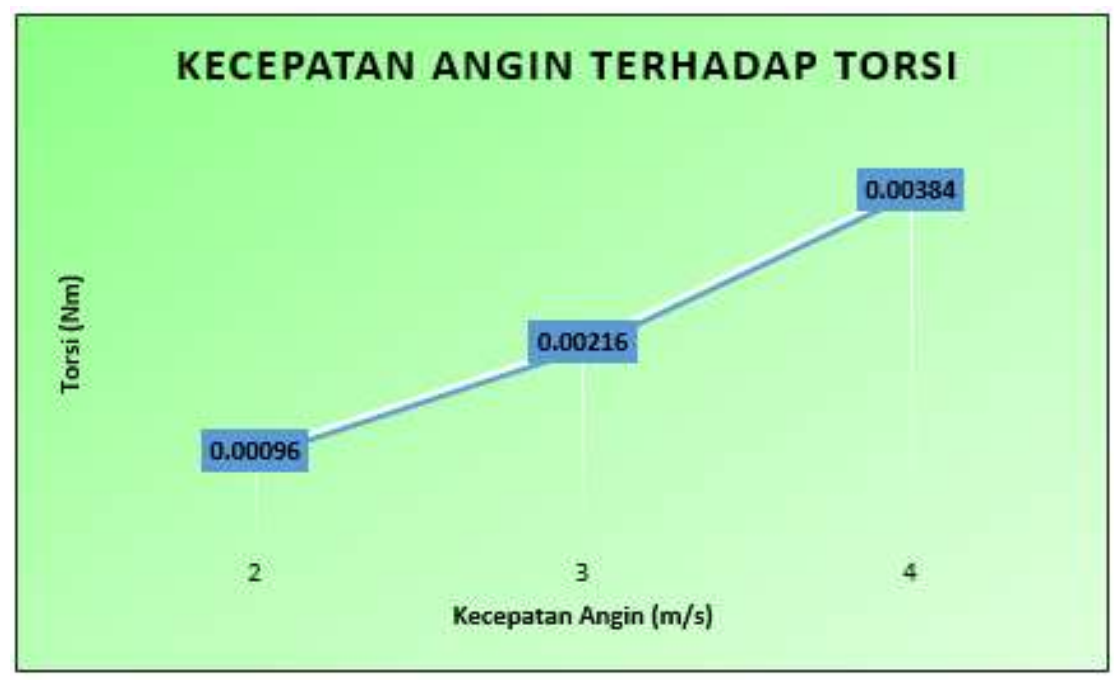

Gambar 4. Grafik Kecepatan Angin Terhadap Torsi

Pada perhitungan nilai Torsi turbin savonius bertingkat, Nm, pada kecapatan angin $3 \mathrm{~m} / \mathrm{s}$ dengan torsi $0.00216 \mathrm{Nm}$ nilai Torsi pada kecapatan angin $2 \mathrm{~m} / \mathrm{s}$ dengan torsi 0.00096

dan kecapatan angin $4 \mathrm{~m} / \mathrm{s}$ dengan torsi $0.00384 \mathrm{Nm}$.

Tabel 2 . Perbandingan Analisis numerikal dengan eksperimen.

\begin{tabular}{|c|c|c|c|c|}
\hline No & $\begin{array}{c}\text { Tingkat } \\
\text { sudu }\end{array}$ & $\begin{array}{c}\text { Kecepatan } \\
\text { angin }\end{array}$ & SS (Perhitungan) & $\begin{array}{c}\text { SS ( Pengujian) } \\
\text { Alumunium }\end{array}$ \\
\hline 1 & 6 & 2 & 191.0828 & 180.64 \\
\hline 2 & 6 & 3 & 286.6242 & 271.43 \\
\hline 3 & 6 & 4 & 382.1656 & 358.7 \\
\hline
\end{tabular}




\section{KESIMPULAN}

Berdasarkan hasil dari analisa numerikal dan Eksperimen turbin angin savonius bertingkat maka dapat di ambil kesimpulan sebagai berikut :

1. Secara numerikal putaran shaft speed pada turbin angin savonius bertingkat Dengan kecepatan angin 4 $\mathrm{m} / \mathrm{s}$.putaran maksilal $382.166 \mathrm{Rpm}$.

2. Kecepatan angin memiliki pengaruh yang bersar terhadap kinerja turbin angin savonius, semakin besar kecepatan angin maka putaran turbin juga semakain cepat. pada kecepatan angin $4 \mathrm{~m} / \mathrm{s}$ turbin savonius dengan bahan sudu alumunium menghasilkan putaran $358.7 \mathrm{rpm}$

\section{DAFTAR PUSTAKA}

[1] Debnath, Pinku. (2013) Flow Physics Analysis of Three-Bucket Helical Savonius Rotor at 90 DegreeTwist Angle Using CFD
[2] Haqi. M. H, Gunawan. N dan Musyafa. A. (2013) Rancang Bangun Turbin Angin Vertikal Jenis Savonius dengan Variasi Jumlah Blade Terintegrasi Circular Shield untuk Memperoleh Daya Maksimum. Jurusan Teknik Fisika, Fakultas Teknologi Industri, Institut Teknologi Sepuluh Nopember (ITS)

[3] M. Suprapto. Iskendar (2016) analisis Pengaruh jumlah sudu terhadap unjuk kerja pada turbin angin vertikal tipe savonius dengan metode taguchi.

[4] Maulana, Yassyir. (2018). Perancangan Vertical Axis Wind Turbine (VAWT) Jenis Straight Blade. Journal of Industrial Engineering and Operation Management (JIEOM) Vol.01 No.02. Publ. UPT. Publikasi dan Pengelolaan Jurnal.

[5] Mohammed Hadi Ali. (2013). Experimental Comparison Study for Savonius Wind Turbine of two and Tree Blades At low Wind Speed. International Journal of modern Engineering Research (IJMER), Vol.3-Issue 5. 2978-2986. Lecturer University of Mustansiriya.

[6] Sargolzaei, (2007). Prediction of the power ratio in wind turbine Savonius rotors using artificial neural networks

[7] Sigemes, F., (2015) savonius wind rotor basics. University Centre in Svalbard (UNIS), Norway.

[8] Sigurd J. Savonius, The wing-rotor in theory and practice, Publ. SAVONIUS \& CO., Helsingfors, Finland, 1-39, 1925 